\title{
The influence of expertise in simultaneous interpreting on non-verbal executive processes
}

\section{Carolina Yudes*, Pedro Macizo and Teresa Bajo}

Department of Experimental Psychology, University of Granada, Granada, Spain

\section{Edited by:}

Judith F. Kroll, Penn State University, USA

\section{Reviewed by:}

Gigi Luk, Rotman Research Institute

at Baycrest, Canada

Annette de Groot, University of

Amsterdam, Netherlands

*Correspondence:

Carolina Yudes, Departamento de Psicología Experimental, Campus de Cartuja s/n, Universidad de Granada, 18071, Granada, Spain

e-mail:cyudes@ugr.es
This study aimed to explore non-verbal executive processes in simultaneous interpreters. Simultaneous interpreters, bilinguals without any training in simultaneous interpreting, and control monolinguals performed the Wisconsin card sorting task (WCST; Experiment 1) and the Simon task (Experiment 2). Performance on WCST was thought to index cognitive flexibility while Simon task performance was considered an index of inhibitory processes. Simultaneous interpreters outperformed bilinguals and monolinguals on the WCST by showing reduced number of attempts to infer the rule, few errors, and few previouscategory perseverations. However, simultaneous interpreters presented Simon effects similar to those found in bilinguals and monolinguals. Together, these results suggest that experience in interpreting is associated with changes in control processes required to perform interpreting tasks.

Keywords: simultaneous interpreting, bilingualism, executive processes, cognitive flexibility, inhibitory processes

\section{INTRODUCTION}

In the last two decades, an important issue within bilingual studies has been whether proficiency in two or more languages results in cognitive advantages. Previous studies have shown that becoming expert in a motor or cognitive domain sometimes leads to generalization of the acquired advantage to other domains (Die et al., 2009; Gruber et al., 2010). We understand expertise as the set of special skills and knowledge derived from extensive experience within a knowledge domain (Hoffman, 1998). Expertise may lead to a reorganization of the cortical functions as the result of this extensive experience (Maguirre et al., 2000; Mechelli et al., 2004; Gruber et al., 2010). For example, skilled video-game players have been found to develop better attentional processing (Green and Bavelier, 2003) and better skills to perform mental rotations and to work with iconic representations than non-players in playing the game Tetris (Sims and Mayer, 2002). Similarly, frequent internet communicators have been found to be more skilled at attending visual stimuli, and at planning and processing simultaneous information than infrequent internet communicators (Johnson, 2008). In addition, extensive training on dividing attention improves performance on complex concurrent tasks (Spelke et al., 1976).

According to this view about expertise, bilingual speakers who have to negotiate the use of their two languages in their daily lives can be considered experts at managing competition and resolving conflicts (Bialystok et al., 2005; Kroll and Link, 2007; Bialystok, 2008). The constant use of language selection processes to maintain activation of one language and avoiding competition from the other language may increase the ability to ignore irrelevant information and develop efficient attentional control across all domains of perceptual and cognitive processing. The idea is that the executive control mechanism in charge of resolving competition in language related tasks is similar to the control mechanism acting in the domains of perception, attention, or action (Bialystok, 2001; Kan and Thompson-Schill, 2004; Abutalebi and Green, 2007). Thus, numerous studies have examined whether control processes in language selection generalize to non-linguistic tasks involving conflict resolution (Costa et al., 2006, 2009; Bialystok, 2007; Bialystok et al., 2008). Results of these studies have provided evidence for this superior executive functioning in bilinguals when they perform tasks such as the Simon task (Bialystok, 2006; Bialystok et al., 2008), the flanker task (Costa et al., 2008), the task-switching paradigm (Prior and MacWhinney, 2010), or the anti-saccade task (Bialystok et al., 2006a).

An extreme situation for between-language control is simultaneous interpreting (SI). In this task, a spoken message in a source language (SL) must be reformulated and then produced into the target language (TL). The challenge for control comes from the fact that these processes occur in simultaneity. The interpreter receives part of a message in the SL, while she/he is mentally translating and verbally producing previous parts of the message in the TL (Gerver, 1971). Thus, the two language systems have to be simultaneously active for comprehension and production (de Groot and Christoffels, 2006). Executive control is considered essential for this task since the SL has to be selected for comprehension, while the TL has to be selected for production; therefore, strong coordination between the languages is needed to move from one language to the other (Gile, 1991, 1997; Lambert et al., 1995; Danks et al., 1997; Christoffels and de Groot, 2004). In fact, learning to interpret involves attentional training to achieve mental flexibility and coordination so that no information loss and interference between languages occurs. As experience increases, resource allocation is carried out more automatically and efficiently (Gile, 1995, 2009; Liu, 2008). In this regard, simultaneous interpreters acquire important skills for controlling their attentional resources, so they 
can be considered as "experts in executive control." Hence, our argument here is that SI is an extreme situation for language control and, as a consequence, extensive experience in interpreting may result in superior executive functioning.

Interestingly, language control in interpreting may differ from language control in other bilingual contexts. It has been observed that both interpreters and ordinary bilinguals experience interference from the language that is not in use (e.g., Rodriguez-Fornells et al., 2005; Kaushanskaya and Marian, 2007). However, the challenge for the bilingual is to select the appropriate language and to avoid this interference from the non-TL (Grosjean, 2001), whereas the challenge for the interpreter is to keep the two languages active and continuously switch from one language to another. Bilingual models of language control propose that language selection is regulated by inhibitory processes in both language comprehension (BIA model, Dijkstra and van Heuven, 1998) and language production (Green, 1998). These models propose that selection of the appropriate language is achieved by inhibition of the competing non-appropriate language. However, there is some evidence that inhibition may not be the mechanism by which the interpreters achieve language control. In a recent study, Ibáñez et al. (2010) asked bilinguals without any training or experience in interpreting, not in any other form of formal translation (hence forth these ordinary bilinguals will be referred simply as "bilinguals") and professional translators matched in language proficiency to read sentences word-by-word at their own pace. In all the trials participants were asked to read and understand the sentences, and to repeat them in the language of presentation. The input language (Spanish: L1 and English: L2) varied from trial to trial in an unpredictable manner. In addition, cognate words (words that share similar form and meaning in two languages) were included in some of the sentences. These two manipulations were critical: the cognate effect (that is, the difference in processing time and/or errors between cognates and non-cognates) is often thought to indicate that bilingual's two languages are simultaneously activated (Kroll and Stewart, 1994; Dijkstra et al., 1999; Macizo and Bajo, 2006); whereas switching between the languages of input provides a way to examine whether the non-appropriate language is indeed inhibited. Specifically, if the latter holds, an asymmetrical switching cost may be expected to occur, the switching cost being larger when the input language changes from the less dominant L2 to the more dominant L1 than when it changes from L1 to L2 (Meuter and Allport, 1999). The results of this experiment indicated that lexical processing depended on the participants' experience in professional translation. Experienced translators were faster at processing cognate words relative to control words, indicating that the two languages were active during the course of reading. In addition, the translators did not seem to inhibit the irrelevant language because there was no asymmetrical switching cost. In contrast, the bilinguals presented larger switching cost when switching to L1 than when switching to L2 (asymmetrical pattern of switching cost) indicating that they inhibited the non-TL when they understood sentences in their alternative language. Moreover, the bilinguals processed cognate and control words equally rapid indicating that only the language in which the sentences were presented was active in each trial.
This would suggest that bilinguals and translators negotiate their two languages in different ways and it is possible that these differences extend to differences between bilinguals and interpreters (translators with professional experience in interpreting tasks) in executive functions. More specifically, it might be possible that interpreters had formed strong connections between lexical equivalents as a result of their practice in interpreting which would favor the automatic activation of their two languages. In addition, it is also possible that difference between ordinary bilinguals and interpreters extends to the enhancement of different executive functions.

Hence, we aimed to explore this last hypothesis by comparing professional interpreters with bilinguals and monolingual participants in two tasks tapping different aspects of executive control: the Wisconsin card sorting test (WCST) and the Simon task. These tasks were selected following the theoretical framework provided by Miyake and colleagues (Miyake et al., 2000; Friedman and Miyake, 2004; Friedman et al., 2006). In different studies they have investigated the psychometric relationships between the tasks that are commonly used to assess executive control and they have identified three separable control functions: "shifting" between tasks and mental sets (also called "flexibility"), "inhibition" of unwanted responses, and "updating" and monitoring of working memory (WM) representations. In the current study, we focused on two of these control functions, shifting and inhibition. From our previous analyses, we hypothesized that the interpreters should show superior performance in tasks requiring "shifting" (e.g., WCST), whereas bilinguals may be superior in tasks requiring "inhibiting" unwanted responses (e.g., Simon task). The WCST is a stimulus categorization task in which the participants have to infer a sorting rule that allows them to arrange a set of cards. This rule is modified during the task and the participants have to infer new rules continuously. The participants receive information on whether their responses are correct or not, but they are not informed about the underlying rule. Thus, this test reflects the participant's ability to switch their mental set and, therefore, her/his mental flexibility to infer the rule. On the other hand, the Simon task is used to capture inhibitory control of prepotent responses in the presence of conflicting information. In the task, the participants have to pay attention to one stimulus dimension (i.e.,color) while ignoring another irrelevant dimension (i.e., spatial position). However, the typical result is that participants cannot ignore the information about the stimulus location and they show longer reaction times when there is conflict between the spatial information provided on the screen (left or right) and the response key (left or right). This result is known as Simon effect (Lu and Proctor, 1995, for a review, Simon, 1990) which indicates that participants are not able to resist the misleading information and that they have difficulties inhibiting the response. A more detailed description of WCST and Simon tasks used in this study will be provided in the next sections.

In the present study professional interpreters were compared with bilinguals and monolinguals in two cognitive functions. In Experiment 1, we used the WCST to evaluate the cognitive function of shifting, while in Experiment 2, we used the Simon task to evaluate the ability of inhibiting irrelevant information. 


\section{EXPERIMENT 1 WISCONSIN CARD SORTING TEST MATERIALS AND METHODS \\ Participants}

Forty-eight participants served as volunteers in this study. Participants were paid for their participation. The first group was composed of 16 Spanish monolingual speakers from the University of Granada (11 female). The second group was composed of 16 fluent bilingual speakers (10 female) with Spanish as their native language and English as their L2. Finally, the third group was composed of 16 professional interpreters ( 8 female) with a mean of 10.83 years of experience in interpreting (participants' characteristics can be seen in Table 1).

Participants completed the Raven progressive matrices intelligence test to control for general intelligence. An ANOVA conducted on the total scores indicated that the groups did not differ, $F<1$. Hence, possible between-group differences cannot be due to unspecific global skills (see Table 1).

In addition, since studies on executive functioning have observed differences associated to WM span (Padilla et al., 2005), the participants were assessed in their WM amplitude. Thus,

Table 1 | Characteristics of participants in the study.

\begin{tabular}{|c|c|c|c|}
\hline & Monolinguals & Bilinguals & Interpreters \\
\hline Age & $21.65(2.91)$ & $25.68(3.17)$ & $36.31(11.85)$ \\
\hline WM span & $3(0.67)$ & $3.26(0.65)$ & $4.29(0.54)$ \\
\hline Raven & $27(30.11)$ & $31.93(29.98)$ & $35.62(24.34)$ \\
\hline \multicolumn{4}{|c|}{ SECOND LANGUAGE (L2) PROFICIENCY QUESTIONNAIRE } \\
\hline Fluency (total) & & $8.35(0.47)$ & $8.62(0.86)$ \\
\hline Reading & & $8.78(0.75)$ & $8.87(0.95)$ \\
\hline Writing & & $7.93(1.06)$ & $8.49(0.96)$ \\
\hline Speaking & & $8.15(0.88)$ & $8.43(1.03)$ \\
\hline Speech & & $8.56(0.81)$ & $8.68(1.01)$ \\
\hline \multicolumn{4}{|l|}{ comprehension } \\
\hline Frequency of use & & $4.64(1.29)$ & $4.91(1.48)$ \\
\hline \multicolumn{4}{|l|}{ (days per week) } \\
\hline Write & & $4.75(1.84)$ & $4.68(1.66)$ \\
\hline Read & & $5.49(1.41)$ & $5.37(1.54)$ \\
\hline Speak & & $3.68(2.35)$ & $4.68(1.88)$ \\
\hline Time living in $L 2$ & & $14.48(6.49)$ & $12.11(4.07)$ \\
\hline \multicolumn{4}{|l|}{ speaking countries } \\
\hline \multicolumn{4}{|l|}{ (months) } \\
\hline \multicolumn{4}{|l|}{ PROFESSION } \\
\hline \multirow[t]{5}{*}{ Main } & Under & Touristic guide/ & Interpreting \\
\hline & graduated & English teacher/ & \\
\hline & students & Ph. D. students & \\
\hline & & on English & \\
\hline & & philology & \\
\hline
\end{tabular}

Secondary

Touristic guide/ English teacher/ international

business

The self-report in the language history questionnaire ranged from 1 to 10 where 1 was not fluent and 10 very fluent. Means and SD (in brackets) are reported. participants performed a Spanish version of the Reading Span Test (Daneman and Carpenter, 1980) to assess their WM capacity. In this test sets of sentences are shown and participants are instructed to read each sentence aloud and to recall the last word of each sentence at the end of the set. The number of sentences in the set increases gradually from two to six. The size of the largest set of sentences in which all last words are recalled correctly represents the participant's memory span. Subjects with 3.5 or higher scores are usually considered to have a high memory span (Miyake et al., 1994). An ANOVA conducted on the mean WM span showed significant differences among the groups, $F(2,45)=14.19, \mathrm{MSE}=0.39, p<0.05$. These differences were due to the higher memory span for the interpreters relative to the monolinguals, $F(1,45)=24.52, p<0.05$, and bilingual speakers, $F(1,45)=17.94, p<0.05$ (means can be seen in Table 1 ). There were no differences in WM span between monolinguals and bilinguals $(p>0.05)$. The larger memory span of the interpreters replicates previous results (Bajo et al., 2000; Padilla et al., 2005).

The interpreters were also older than the bilinguals and monolinguals, $F(2,45)=17.33, \mathrm{MSE}=53.08, p<0.05$ (see Table 1 ). Therefore, in the analyses that we report below we first include the entire group of interpreters, then we performed the same analyses with a smaller interpreter group $(N=8)$ equated in age (and other demographic variables) to the bilingual and monolingual groups. Since the pattern of results was identical, we are reporting only those in which the complete group of 16 interpreters was included.

We also asked the bilinguals and interpreters to fill out a language history questionnaire (see Macizo and Bajo, 2006; Macizo et al., 2010) to assess their language proficiency and the history of their two languages. The mean scores for each group in reading, writing, speaking, and speech comprehension are reported in Table 1. The analyses carried out on these data revealed that there were no differences between bilinguals and interpreters in their general L2 proficiency, $F(1,30)=1.15, \mathrm{MSE}=0.48, p>0.05$, or in the frequency of use of their $\mathrm{L} 2, F(1,30)=0.30, \mathrm{MSE}=1.93$, $p>0.05$. In order to guarantee maximal comparability within our bilingual groups (interpreters and bilinguals), we selected only non-balanced bilingual speakers (the interpreters were all unbalanced-late bilinguals). Consequently, both groups had similar proficiency, history, and use of their second language, although they differed in their interpreting experience.

In addition to the participants' mean age, mean WM span, Raven scores, and proficiency measures, Table 1 shows the time that the participants spent living in L2 speaking countries and their profession/occupation. The main difference between ordinary bilinguals and interpreters was their educational training in translation and interpreting, only the latter having been formally trained in interpreting. In addition, the interpreters had practiced professional interpreting for a long time $(M=10.83$ years $)$ while the bilinguals lacked such professional experience. Professional interpreting was the interpreters' main occupation, although they also had occupations similar to the main occupations of ordinary bilinguals. 


\section{Materials and procedure}

We used the Spanish version of the WCST (Cruz-Lopez, 2001). The test is composed of 128 response-cards and 4 stimulus-cards depicting geometric figures. The figures differ along three dimensions: shape (cross, circle, triangle, or star), color (red, blue, yellow, or green), and number of items (one, two, three, or four). These dimensions are combined to compose the response-cards which included one or more figures with the same shape and color, for example, cards with one green cross, cards with three yellow circles, cards with four blue triangles, etc. On the other hand, the stimulus-cards depicted one red triangle; two green stars; three yellow crosses; and four blue circles.

The experiment was conducted in a quiet and well lit room. The stimulus-cards were given to the participants and they were asked to sort each response-card placing it on one of the stimuluscards according to a sorting rule. Participants were not informed of the particular sorting rule, but every time a response-card was sorted, they received positive or negative feedback depending on whether the response matched the sorting rule. This feedback was provided to allow the participant to guess the rule and to make correct responses. However, after 10 consecutive correct responses the sorting rule changed. The participants were not informed of this change of rule but they received negative feedback if they continued sorting the cards with the previous rule. Thus, through negative and positive feedback participants should again guess the correct rule. The first sorting rule was based on the color dimension, the second on the shape, and the third on the number. The rules were repeated twice before completing the test. The task finished either when the participant inferred the six rules (color, shape, number, twice each) successfully or when the participant reached the maximum of 128 trials.

\section{RESULTS}

First, we report analyses on global performance (number of completed categories, number of attempts, and number of errors). Then, we report detailed analyses on different types of error to capture differences in mental flexibility (Barceló and Knight, 2002).

\section{Global performance}

Number of completed categories. The number of categories ranged from 0 to 6 ( 0 meant that the participant was not able to complete 10 consecutive correct responses to any of the categories and six meant that the participant successfully achieved all the series). The results of the ANOVA on the number of completed categories indicated that there were no differences among the groups, $F(2,45)=2.62, \mathrm{MSE}=2.21, p>0.05, \eta_{p}^{2}=0.11(\mathrm{see}$ Table 2).

Number of attempts. The analysis on the number of attempts to find the correct sorting rule (max. 128) revealed a main effect of group, $F(2,45)=7.92, \mathrm{MSE}=426.21, p<0.05$. The interpreters needed fewer attempts to guess the rule (90.68 out of the 128 possible attempts) than the rest of the groups. The differences were significant when compared to the monolinguals, $F(1,45)=14.01, p<0.05$, and to the bilinguals, $F(1,45)=9.29$, $p<0.05, \eta_{p}^{2}=0.26$, whereas there were no differences between monolinguals and bilinguals, $F<1$ (see Table 2 ).
Table 2 | Mean number of completed categories, attempts, and errors (and SD) for each group of participants. $\mathrm{Cl}$ : $95 \%$ confidence interval.

Global performance

\begin{tabular}{llll}
\cline { 2 - 4 } & $\begin{array}{l}\text { Completed } \\
\text { categories }\end{array}$ & $\begin{array}{l}\text { Number of } \\
\text { attempts }\end{array}$ & $\begin{array}{l}\text { Number of } \\
\text { errors }\end{array}$ \\
\hline Monolinguals & $4.37(1.66)$ & $118(14.85)$ & $41.59(16.64)$ \\
$\mathrm{Cl}(95 \%)$ & $3.48-5.26$ & $110.08-125.91$ & $32.73-50.47$ \\
Bilinguals & $4.56(1.45)$ & $112.93(21.05)$ & $40.62(21.30)$ \\
$\mathrm{Cl}(95 \%)$ & $3.78-5.34$ & $101.72-124.15$ & $29.27-51.97$ \\
Interpreters & $5.50(1.31)$ & $90.68(24.79)$ & $22.37(20.12)$ \\
$\mathrm{Cl}(95 \%)$ & $4.79-6.19$ & $77.47-103.89$ & $11.65-33.09$
\end{tabular}

Maximum number of completed categories $=6$; maximum number of attempts $=128$.

Number of errors. The analysis on the number of errors showed a reliable main effect of group, $F(2,45)=4.95, \mathrm{MSE}=378.59$, $p<0.05, \eta_{p}^{2}=0.18$, so that the interpreters had the lower percentage of errors as compared to the monolinguals, $F(1$, $45)=7.81, p<0.05$, and the bilinguals, $F(1,45)=7.03, p<0.05$. There were not significant differences between monolinguals and bilingual participants, $F<1$ (see Table 2).

Types of error. The WCST manual (Heaton et al., 1993) distinguishes between perseverative and non-perseverative errors. The perseverative errors are failures to change the mental rule after receiving negative feedback so that the person continues sorting the cards according to the previous-category dimension despite feedback indicating that the response was wrong. The non-perseverative errors are the normal errors needed to learn the new rule. This type of error reflects an attitude to change the response after receiving disconfirming feedback (Barceló, 1999). An ANOVA was conducted to examine the distribution of these types of error in each group. The results of this analysis yielded a significant interaction between-group and type of error, $F(2$, $45)=11.92, \mathrm{MSE}=20.29, p<0.05, \eta_{p}^{2}=0.18$. This interaction indicated that there were no group differences when analyzing non-perseverative errors, $F(2,45)=1.38, p>0.05$. However, the effect of group was significant when analyzing the percentage of perseverative errors, $F(2,45)=8.39, p<0.05$. In this case, interpreters showed fewer errors than the monolinguals, $F(1$, $45)=15.29, p<0.05$, and the bilinguals, $F(1,45)=9.07, p<0.05$. There were no differences between monolinguals and bilinguals, $F<1$ (see Table 3).

To further understand the effect of expertise in interpreting, we performed additional analyses on the perseverative errors. Thus, we categorized these errors into perseverations to the immediately preceding category and perseverations to a different-category (Hartman et al., 2001). Previous-category perseverations reflect lack of flexibility to change the mental set to a new rule, while different-category perseverations reflect the understanding that the previous rule is no longer correct but there is an unsuccessful attempt to infer a new rule. The ANOVA performed on the number of previous-category perseverations revealed a significant effect of group, $F(2,45)=6.16$, MSE $=51.56, p<0.05, \eta_{p}^{2}=0.21$, with 
Table 3 | Mean number (and SD) of different types of errors (perseverative and non-perseverative), and mean number (and SD) of types of perseverations (previous-category and different-category perseverations) in each group of participants.

\begin{tabular}{lcccc}
\hline Group & \multicolumn{2}{c}{ Types of error } & \multicolumn{2}{c}{ Types of perseverative errors } \\
\cline { 2 - 3 } & Perseverative & Non-perseverative & Previous-category & Different-category \\
\hline ERROR SCORES & $19.46(9.29)$ & $15.42(8.25)$ & $12.98(7.19)$ & $3.03(3.24)$ \\
Monolinguals & $16.50(10.13)$ & $18.50(9.24)$ & $11.12(8.94)$ & $3.18(4.95)$ \\
Bilinguals & $6.56(8.49)$ & $13.50(8.21)$ & $4.50(4.77)$ & $0.56(1.15)$ \\
Interpreters & & &
\end{tabular}

the interpreters showing fewer previous-category perseverations than the monolinguals, $F(1,45)=11.16, p<0.05$, and the bilinguals, $F(1,45)=6.79, p<0.05$. There were no differences between monolinguals and bilingual participants $(p>0.05)$. In contrast, the ANOVA on the number of different-category perseverations showed marginally significant differences between the groups, $F(2$, $45)=2.82, \mathrm{MSE}=12.22, p=0.06, \eta_{p}^{2}=0.11$ (means can be seen in Table 3). To avoid the problem of unequal variance across cells (because of the reduced number of errors) we performed also analyses with the arcsine transformation of these values. The results of these analyses were the same as those reported here. In addition, to control for the possible non-parametric distribution of errors, non-parametric analyses were performed (Friedman ANOVAs; see Friedman, 1940). The results of these analyses were the same as those reported here.

Because the group of interpreters had larger WM capacity than the groups of monolinguals and bilinguals, we decided to explore whether the observed differences were due to differences in this capacity. Thus, we ran a new series of analyses exploring the role of WM span. Since monolingual and bilingual participants had a similar performance on the WCST and comparable WM capacity (smaller than the interpreters), we pooled them out and divided them up according to their WM. In this way, we composed a group of 16 non-interpreters (eight monolinguals and eight bilinguals) with low WM capacity (with scores below 3.5 in the Reading span test; $M=2.63, \mathrm{SD}=0.39$ ), and a group of 16 noninterpreters (eight monolinguals and eight bilinguals) with high WM capacity (with scores greater than 3.5 in the Reading span test; $M=3.62$, SD $=0.59$ ), and compared them with the group of professional interpreters with high WM span $(M=4.29, \mathrm{SD}=0.54)$. An ANOVA revealed that WM span was similar in the high span participants and interpreters $(p>0.05)$ and both groups scored higher than the low span participants (all $p s<0.05$ ).

In these new analyses, the ANOVA on the number of completed categories did not reveal differences among the span groups, $F(2,45)=2.62, \mathrm{MSE}=2.21, p>0.05, \eta_{p}^{2}=0.11$ (low span: $M=4.56, \mathrm{SD}=1.45$; high span: $M=4.37, \mathrm{SD}=1.66$; interpreters: $M=5.5, \mathrm{SD}=1.31)$. The analysis on the number of attempts to guess the sorting rule showed a main effect of group, $F(2,45)=7.65, \mathrm{MSE}=430.09, p<0.05, \eta_{p}^{2}=0.25$. The interpreters needed fewer attempts to guess the rule $(M=90.68$, $\mathrm{SD}=24.79)$ than both low span $(M=116.45, \mathrm{SD}=18.06), F(1$, $45)=12.34, p<0.05$, and high span participants $(M=114.48$, $\mathrm{SD}=18.68), F(1,45)=10.53, p<0.05$. No differences were found between high and low span participants $(p>0.05)$. In addition, the interpreters showed fewer perseverative errors $(M=6.56$, $\mathrm{SD}=8.49)$ than the low span $(M=18.08, \mathrm{SD}=9.65), F(1$, $45)=11.98, p<0.05$, and the high span participants $(M=17.88$, $\mathrm{SD}=10.03), F(1,45)=11.56, p<0.05$. No differences were found between the low and high span groups $(p>0.05)$. Similarly, the number of perseverations to the previous-category was significantly lower for the interpreters $(M=4.5, \mathrm{SD}=4.77)$ than for the low $\operatorname{span}(M=12.57, \mathrm{SD}=8.26), F(1,45)=10.02, p<0.05$, and the high span participants $(M=11.53, \mathrm{SD}=8.05), F(1$, $45)=7.62, p<0.05$. No differences were found between low and high span groups, $p>0.05$. Finally, the number of perseverations to a different-category was smaller for the interpreters $(M=0.56$, $\mathrm{SD}=1.15)$ than for the low span $(M=2.31, \mathrm{SD}=3.34), F(1$, $45)=2.07, p<0.05$, and the high span participants $(M=3.89$, $\mathrm{SD}=4.78), F(1,45)=7.58, p<0.05$. The low and high span groups did not differ, $p>0.05$.

\section{DISCUSSION}

In summary, although the interpreters did not differ from monolinguals or bilinguals in the global number of completed categories, they were able to complete the task in a more efficient way. This efficiency was observed in the reduced number of attempts to infer the sequence of rules and in the smaller number of errors. Importantly, analyses on the type of errors indicated that the main differences between the interpreters and the other groups were observed in the reduced number of perseverative errors in the group of interpreters. Furthermore, when we examined the types of perseverations, we found reliable group differences in the perseveration from previous-category with the interpreters having the lowest number of this type of error. This pattern of results suggests that the interpreters were able to update the task-relevant information efficiently and rapidly change their hypothesis when needed. The interpreters looked for alternative solutions to negative feedback and they reorganized the elements of the problem faster than monolingual or bilingual speakers. Interpreters had better performance in the WCST even when they were compared with high span bilingual/monolingual participants, suggesting that their advantage on "shifting" or mental flexibility was due to their interpreting experience and not to their larger WM capacity.

\section{EXPERIMENT 2 SIMON TASK}

In Experiment 2, we examined whether the interpreters would also show better performance than the bilinguals and monolinguals in tasks requiring inhibition of conflicting responses (e.g., the Simon task). As we mentioned, whereas interpreting requires excellent 
switching skills and mental flexibility, there are data suggesting that interpreters might not inhibit the alternative language while interpreting (Ibáñez et al., 2010). If this was the case, very likely the interpreters would not show superior performance in the Simon task.

\section{MATERIALS AND METHODS Participants}

The same participants that carried out Experiment 1 also participated in Experiment 2.

\section{Materials and procedure}

In the Simon task, participants had to respond to color stimuli presented on an irrelevant spatial location. In the task, each trial started with a fixation point $(+)$ that remained on the center of the screen for $350 \mathrm{~ms}$. Then, a colored square (red or blue) appeared on either the left or the right side of the fixation point and participants were instructed to press the response key corresponding to the color of the square as fast as possible. The response keys were also located left or right on the keyboard. Thus, if the colored square was red, the participant had to press the response key marked with a red sticker located on the right side of the keyboard ("intro" key); if the square was blue, the participant had to press the response key marked with a blue sticker located on the left side of the keyboard ("tab" key). If there was no response, the colored square remained on the screen for $2000 \mathrm{~ms}$.

Depending on the location of the colored square on the screen, the trials could be congruent or incongruent. Thus, in congruent trials the location of the stimulus coincided with the position of the response key (e.g., red square on the right), whereas in the incongruent trials the position of the stimulus and the response key did not match, that is, the stimulus was presented on the opposite side of the correct response key (e.g., red square on the left side of the screen). In addition, there were control trials in which stimuli were centered on the screen. There were a total of 150 trials. Participants were given 24 practice trials with feedback before the experimental trials to familiarize them with the response keys. The remaining 126 trials were divided in three blocks of 42 experimental trials each. In each block there were 14 incongruent trials, 14 congruent trials, and 14 control trials, which were randomly presented. Participants received instructions to respond to the color of the squares, and they were told that the locations of the stimuli were irrelevant to perform the task.

The sequence of events and data collection was controlled by E-prime experimental software, 1.1 version (Schneider et al., 2002).

\section{RESULTS}

We performed separate ANOVAs (Group $\times$ Type of Cue) on the number of correct responses and on response times (RT).

\section{Response times}

Response times faster than $200 \mathrm{~ms}$ or slower than $1200 \mathrm{~ms}$ were excluded from the analysis $(0.23 \%)$. RTs associated to incorrect responses were also filtered out $(2.5 \%)$.

The analysis on RTs indicated that the effect of group was not significant, $F<1$. A main effect of type of cue was observed,
Table 4 | Mean reaction times (RT; in milliseconds) and percentage of correct responses (\% CR and SD) for each group of participants for the Simon task. $\mathrm{Cl}: \mathbf{9 5 \%}$ confidence interval.

\begin{tabular}{|c|c|c|c|}
\hline \multicolumn{4}{|c|}{ Type of trials } \\
\hline & Congruent & Incongruent & $\mathrm{Cl}(95 \%)$ \\
\hline & & & congruent/incongruent \\
\hline \multicolumn{4}{|c|}{ MONOLINGUALS } \\
\hline RT & $441.37(66.58)$ & $475.86(53.23)$ & $405.7-477.1 / 447.8-504.2$ \\
\hline$\% \mathrm{CR}$ & $98.37(1.82)$ & $93.11(7.82)$ & $97.4-99.3 / 88.9-97.2$ \\
\hline \multicolumn{4}{|c|}{ BILINGUALS } \\
\hline RT & $424.34(57.26)$ & $463.11(60.43)$ & $393.8-454.8 / 430.8-495.3$ \\
\hline$\% \mathrm{CR}$ & $98.66(1.21)$ & $93.01(7.94)$ & $98.1-99.3 / 88.7-97.2$ \\
\hline \multicolumn{4}{|c|}{ INTERPRETERS } \\
\hline RT & $445.35(77.07)$ & $483.06(73.01)$ & $404.2-486.4 / 444.1-522.1$ \\
\hline$\% \mathrm{CR}$ & $99.25(1.13)$ & $96.28(3.88)$ & $98.6-99.8 / 94.2-98.3$ \\
\hline
\end{tabular}

$F(2,90)=59.79, \mathrm{MSE}=549, p<0.05, \eta_{p}^{2}=0.57$. This effect showed the typical Simon effect, that is, significantly slower RTs to incongruent trials $(M=474.01 \mathrm{~ms}, \mathrm{SD}=62.01)$ relative to the congruent trials $(M=437.02, \mathrm{SD}=66.75$; see Table 4). The interaction between type of cue and group was not significant, $F<1$, indicating that the Simon effect was equivalent for all the groups (Simon effect (RT): monolinguals $=34.49 \mathrm{~ms}$; bilinguals $=38.74 \mathrm{~ms}$; interpreters $=37.69 \mathrm{~ms}$; Simon effect (correct responses): monolinguals $=-5.25$; bilinguals $=-5.65$; interpreters $=-2.97)^{1}$.

As in the previous experiment, we explored the role of WM on performance in the Simon test. Thus, we carried out new analyses grouping monolinguals and bilinguals and then dividing them up in two groups based on their WM span (see Experiment 1). The analysis on RT when WM span was considered revealed that equivalent Simon effects were present in low span participants, $F(1,15)=12.37, \mathrm{MSE}=785, p<0.05$, high span participants, $F(1,15)=27.71, \mathrm{MSE}=426, p<0.05$ and interpreters, $F(1,15)=25.96, \mathrm{MSE}=438, p<0.05$.

\section{Accuracy analyses}

The analysis performed on the number of correct responses revealed that there were no significant differences among the groups, $F(2,45)=1.45$, MSE $=28.71, p>0.05, \eta_{p}^{2}=0.05$. However, the effect of type of cue was significant, $F(2,45)=25.97$, $\mathrm{MSE}=19.79, p<0.05, \eta_{p}^{2}=0.33$. Thus, all participants made fewer correct responses to incongruent trials $(M=94.13$, $\mathrm{SD}=6.84)$ relative to congruent trials $(M=98.76, \mathrm{SD}=1.44)$. The interaction between-group and type of trial was not significant, $F<1$, revealing similar Simon effect for the three groups (see Table 4).

The analyses in which WM span was considered showed that the decrease in correct responses for incongruent trials relative to the congruent trials was significant in all the groups independently of their WM capacity (low span participants,

\footnotetext{
${ }^{1}$ Simon effect is calculated by subtracting the reaction times (or percentage of correct responses) to congruent trials from those to incongruent trials.
} 
$F(1,15)=8.81, \mathrm{MSE}=32.11, p<0.05$, Simon effect $=-5.95$; high span participants, $F(1,15)=9.63, \mathrm{MSE}=20.39, p<0.05$, Simon effect $=-4.96$; interpreters, $F(1,15)=10.72, \mathrm{MSE}=6.59$, $p<0.05$, Simon effect $=-2.97$ ).

\section{DISCUSSION}

In summary, the interpreters showed Simon effects that were similar in magnitude to those observed in the monolingual and bilingual groups. This finding suggests that experience in interpreting does not necessarily improve the functioning of all executive processes since the type of inhibitory control required by the Simon task seemed to be independent of the exact nature of the prior bilingual language experience. This is important because it suggests that the cognitive advantage of the interpreters is not general, but restricted to the exact cognitive operations needed to perform the interpreting task.

Surprisingly, the bilinguals did not show a reduced Simon effect relative to the monolinguals and interpreters. The lack of superiority of the bilinguals when compared to the monolingual group is inconsistent with other studies that show a bilingual advantage in tasks that involve inhibitory control (Bialystok et al., 2004, 2005, 2006a,b; Bialystok, 2006; Costa et al., 2008; Hernández et al., 2010). For example, Linck et al. (2008) compared the magnitude of the Simon effect in monolingual and bilingual participants and they found the bilinguals to have a significantly smaller Simon effect relative to monolingual participants (see also Bialystok et al., 2004; Bialystok, 2006). In the Section "General Discussion" we will go back to this finding and discuss several possible reasons for not finding a bilingual advantage in our study.

\section{GENERAL DISCUSSION}

The results of Experiment 1 showed that experience in interpreting enhances cognitive flexibility as measured by the WCST. Thus, the interpreters showed fewer attempts to infer the rule, a smaller number of errors and, crucially, fewer previous-category perseverations. This pattern of results suggests that the interpreters were able to update the task-relevant information efficiently and to change their responses accordingly.

In contrast, as shown in Experiment 2, experience in interpreting did not affect performance in the Simon task. Interpreters were not able to avoid interference from the irrelevant location dimension and they showed Simon effects similar in magnitude than those observed in the bilingual and monolingual groups, suggesting that interpreting does not enhance the ability to reduce interference from conflicting responses. Different analyses showed that our results were not due to the participants' WM capacities since interpreters had a better performance than untrained high span participants in the WSCT and both groups showed similar Simon effects.

Our results are consistent with a recent study by Köpke and Nespoulous (2006) comparing professional interpreters, interpreting students, and control subjects in the Stroop task. The results showed that the interpreters were not better than the students and controls in avoiding interference in the Stroop situation. Köpke and Nespoulous (2006) hypothesized that the normal performance of the interpreters in the Stroop task could be due to the reduced validity of this task to measure the attentional skills in
SI. They suggest that because the Stroop task is visual in nature, whereas SI engages meaningful auditory material, there is no transfer from interpreting to Stroop. However, our results suggest that it is not the visual nature of the task that is causing the normal performance of the interpreters since they were superior in the WCST that also involved visual materials. In our opinion, this pattern of results would rather be caused by the processes underlying interpreting than with the modality involved in the tasks. As we mentioned, the results of Ibáñez et al. (2010) suggest that interpreting does not require language inhibition, since the two languages have to be active for comprehension and production during the task. However, mental flexibility to switch from one language to another is crucial during interpreting. Consistent with these ideas, the interpreters in our study show enhanced flexibility, but normal inhibitory control. The overall pattern of performance in the interpreters suggests that, in accordance with our expectations, the interpreters' advantage is selective and restricted to the processes directly involved in interpreting.

In contrast, the bilinguals did not behave as we expected. We predicted that experience in inhibitory control for language selection would result in superior performance in the Simon task; however this prediction was not confirmed. As mentioned, this finding is not consistent with other studies showing bilingual advantages in conflict resolution in tasks such as Simon tasks, flanker tasks (Bialystok et al., 2004; Costa et al., 2008), or numerical Stroop tasks (Hernández et al., 2010). There are several reasons for the discrepancy between our study and previous studies showing a reduced Simon effect for the bilinguals (Bialystok et al., 2004, 2005, 2008; Bialystok, 2006; Costa et al., 2008; Martin-Rhee and Bialystok, 2008).

First, the cognitive consequences of bilingualism are usually more salient for balanced than for unbalanced-late bilinguals (Bialystok, 1988; Kroll and Stewart, 1994). The bilinguals in our study were of the second type (unbalanced-late bilinguals) so that they were equated in language proficiency, history, and use to our group of interpreters. In order to isolate the effect of interpreting experience, our bilinguals and interpreters had to be as similar as possible in their L2 language history, for this reason, we selected participants that acquired their second language late, namely, in adolescence or adulthood. Furthermore, the use of the two languages was also unbalanced, so they used mostly one of their languages during their daily life. Therefore, the fact that our bilinguals did not behave differently from the monolinguals in our study suggests that the cognitive advantages related to bilingualism might only be evident in balanced bilinguals. Second, and despite our previous observations, most of the data reporting a reduced Simon effect come from children and elderly bilinguals, that is, populations with restricted executive functions, while sometimes this bilingual advantage is hard to observe in the case of young adults who are at the peak of their attentional capacities (Bialystok et al., 2005, 2008; Morton and Harper, 2007; Colzato et al., 2008; see Hilchey and Klein, 2011, for a recent review). For example, Bialystok et al. (2005) compared the performance of monolinguals and bilinguals in an age range between 30 and 80 years in the Simon task. Bilingual advantages were found only from 60 years old onward (see also Ryan et al., 2004; Bialystok et al., 2006a). Therefore, these data support the idea that the 
age-related rate of decline is significantly less severe for bilinguals, but also that the bilingual advantage in inhibitory control may be more evident in populations that usually show deficits in executive control. Similarly, Salvatierra and Roselli (2010) compared young and old, balanced and non-balanced bilinguals, and monolinguals in a Simon task. There were simple (two colors) and complex (four colors) Simon conditions. Results indicated that the older bilinguals had better performance than older monolinguals under a simple Simon condition. However, there was no bilingual advantage in the younger sample. Moreover, the advantage was found in bilinguals who despite having acquired their second language later in life used their two languages equally often everyday. Therefore, the authors concluded that the bilingual advantage in inhibitory control might depend on the level of linguistic activation rather than on the level of proficiency or age of acquisition.

\section{CONCLUSION}

In conclusion, our results show that experience in interpreting has positive consequences for executive processing. Interestingly, this advantage was only evident in executive functions directly

\section{REFERENCES}

Abutalebi, J., and Green, D. (2007). Bilingual language production: The neurocognition of language representation and control. J. Neurolinguistics 20, 242-275.

Bajo, M. T., Padilla, F., and Padilla, P. (2000). "Comprehension processes in simultaneous interpreting," in Translation in Context, eds A. Chesterman, N. Gallardo-San Salvador, and Y. Gambier (Amsterdam: John Benjamins), 127-142.

Barceló, F. (1999). Electrophysiological evidence of two different types of error in the Wisconsin Card Sorting Test. Neuroreport 10, 1299-1303.

Barceló, F., and Knight, R. (2002). Both random and perseverative errors underlie WCST prefrontal patients. Neuropsychologia 40, 349-356.

Bialystok, E. (1988). Levels of bilingualism and levels of linguistic awareness. Dev. Psychol. 24, 560-567.

Bialystok, E. (2001). Bilingualism in Development: Language, Literacy, and Cognition. New York: Cambridge University Press.

Bialystok, E. (2006). Effect of bilingualism and computer video game experience on the Simon task. Can. J. Exp. Psychol. 60, 68-79.

Bialystok, E. (2007). Cognitive effects of bilingualism: how linguistic experience leads to cognitive change. Int. J. Biling. Educ. Biling. 10, 210-223.

Bialystok, E. (2008). Cognitive control and lexical access in younger and older bilinguals. J. Exp. Psychol. Learn. 34, 859-873.

Bialystok, E., Craik, F. I. M., Klein, R., and Viswanathan, M. (2004).
Bilingualism, aging, and cognitive control: evidence from the Simon task. Psychol. Aging 19, 290-303.

Bialystok, E., Craik, F. I. M., and Luk, G. (2008). Cognitive control and lexical access in younger and older bilingual. J. Exp. Psychol. Learn. 34, 859-873.

Bialystok, E., Craik, F. I. M., and Ryan, J. (2006a). Executive control in a modified anti-saccade task: effects of aging and bilingualism. J. Exp. Psychol. Learn. 32, 1341-1354.

Bialystok, E., Craik, F. I. M., and Ruocco, A. (2006b). Dual-modality monitoring in a classification task: the effects of bilingualism and ageing. Q. J. Exp. Psychol. 59, 1968-1983.

Bialystok, E., Martin, M., and Viswanathan, M. (2005). Bilingualism across the lifespan: the rise and fall of inhibitory control. Int. J. Biling. 9, 103-119.

Christoffels, I. K., and de Groot, A. M. B. (2004). Components of simultaneous interpreting: a comparison with shadowing and paraphrasing. Biling. Lang. Cogn. 7, 1-14.

Colzato, L., Bajo, M. T., van den Wildenberg, W., Paolieri, D.,Nieuwenhuis, S., La Heij, W., and Hommel, B. (2008). How does bilingualism improve executive control? A comparison of active and reactive inhibition mechanism. J. Exp. Psychol. Learn. 34, 302-312.

Costa, A., Hernández, M., CostaFaidella, J., and Sebastián-Galles, N. (2009). On the bilingual advantage in conflict processing: now you see it, now you don't. Cognition 113, 135-149.

involved in the interpreting tasks. Thus, interpreters showed more mental flexibility than the bilinguals and were faster in changing hypotheses online. This ability is probably associated with the interpreters' skills to alternate between languages continuously and to monitor and correct their own output while reformulating and producing speech in the TL. In contrast, and in agreement with previous data showing that inhibition may not be involved in interpreting (Ibáñez et al., 2010), interpreters were not better than monolinguals or bilinguals at ignoring conflicting information. Future research is required to determine which other aspects of executive processing are modulated by interpreting.

\section{ACKNOWLEDGMENTS}

This research was supported by the doctoral research Grant SEJ2005-00842 to Carolina Yudes, by the research program "Ramón y Cajal" to Pedro Macizo; by grants PSI2009-11094/PSI to Pedro Macizo, and EDU2008-01111 to Teresa Bajo, and CSD200800048 Consolider Ingenio 2010 from the Ministry of Science and Innovation of the Spanish Government; and by Proyecto de Excelencia de la JA-2007 to Teresa Bajo and Pedro Macizo and JA-2008_HUM 3600 to Teresa Bajo.

Costa, A., Hernández, M., and Sebastián-Gallés, N. (2008). Bilingualism aids conflict resolution: evidence from ANT task. Cognition 106, 59-86.

Costa, A., La Heij, W., and Navarrete, E. (2006). The dynamics of bilingual lexical access. Biling. Lang. Cogn. 9, 137-151.

Cruz-Lopez, M. V. (2001). Test de clasificación de tarjetas de Wisconsin. Adaptación española. Madrid: Manual Tea Ediciones S.A.

Daneman, M., and Carpenter, J. (1980). Individual differences in working memory and reading. J. Verb. Learn. Verb. Behav. 19, 450-466.

Danks, J. H., Shreve, G. M., Fountain, S. B., and McBeath, M. K. (1997). Cognitive Processes in Translation and Interpreting. Thousand Oaks: Sage.

de Groot, A. M. B., and Christoffels, I. (2006). Language control in bilinguals: monolingual tasks and simultaneous interpreting. Biling. Lang. Cogn. 9, 189-201.

Die, M. W. G., Green, C. S., and Bavelier, D. (2009). The development of attention skills in action video game players. Neuropsychologia 47, 1780-1789.

Dijkstra, A. F. J., Grainger, J., and van Heuven, W. J. B. (1999). Recognition of cognates and interlingual homographs: the neglected role of phonology. J. Mem. Lang. 41, 496-518.

Dijkstra, A. F. J., and van Heuven, W. J. B. (1998). "The BIA-model and bilingual word recognition," in Localist Connectionist Approaches to Human Cognition, eds J. Grainger and A. M.
B. de Groot (Mahwah, NJ: Erlbaum), 189-225.

Friedman, M. (1940). A comparison of alternative tests of significance for the problem of $\mathrm{m}$ rankings. Ann. Math. Stat. 11, 86-98.

Friedman, N. P., and Miyake, A. (2004). The relations among inhibition and interference control processes: a latent variable analysis. J. Exp. Psychol. Gen. 133, 101-135.

Friedman, N. P., Miyake, A., Corley, R. P., Young, S. E., DeFries, J. C., and Hewitt, J. K. (2006). Not all executive functions are related to intelligence. Psychol. Sci. 17, 172-179.

Gerver, D. (1971). Aspects of Simultaneous Interpretation and Human Information Processing. Unpublished Ph.D. dissertation. University of Oxford, UK.

Gile, D. (1991). Methodological aspects of interpretation (and translation) research. Target 3, 153-174.

Gile, D. (1995, 2009). Basic Concepts and Models for Interpreter and Translator Training. Amsterdam: John Benjamins.

Gile, D. (1997). “Conference interpreting as a cognitive management problem," in Cognitive Processes in Translation and Interpretation, eds. J. H. Danks, G. M. Shreve, S. B. Fountain, and M. K. McBeath (Thousand Oaks: Sage), 196-214.

Green, D. W. (1998). Mental control of the bilingual lexico-semantic system. Biling. Lang. Cogn. 1, 67-81.

Green, S., and Bavelier, D. (2003). Attention video game modifies visual selective attention. Nature 423, 534-537. 
Grosjean, F. (2001). "The bilingual's language modes," in One mind, Two Languages: Bilingual Language Processing, ed J. Nicol (Oxford: Blackwell), 1-22.

Gruber, H., Jansen, P., Marienhagen, J., and Altenmueller, E. (2010). Adaptations during the acquisition of expertise. Talent Dev. Excell. 2, 3-15.

Hartman, M., Bolton, E., and Fehnel, S. (2001). Accounting for age differences on the Wisconsin card sorting test: decreased working memory, not inflexibility. Psychol. Aging 16, 385-399.

Heaton, R. K., Chelune, G. J., Talley, J. L., Kay, G. G., and Curtis, G. (1993). Wisconsin CARD SORTING TEST. Manual Revised and Expanded. Odessa: Psychological Assessment Resources Inc.

Hernández, M., Costa, A., Fuentes, L., Vivas, A., and Sebastián-Galles, N. (2010). The impact of bilingualism on the executive control and orienting networks of attention. Biling. Lang. Cogn. 13, 315-325.

Hilchey, M., and Klein, R. (2011). Are there bilingual advantages on nonlinguistic intereference tasks? Implications for the plasticity of executive control processes. Psychon. Bull. Rev. 18, 625-658.

Hoffman, R. R. (1998). "How can expertise be defined? Implications of research from cognitive psychology," in Exploring Expertise, eds R. Williams, W. Faulkner, and J. Fleck (New York: Macmillan), 81-100.

Ibáñez, A., Macizo, P., and Bajo, M. T. (2010). Language access and language selection in professional translators. Acta Psychol. 135, 257-266.

Johnson, G. M. (2008). Cognitive processing differences between frequent and infrequent Internet users. Comput. Hum. Behav. 24, 2094-2106.

Kan, I., and Thompson-Schill, S. (2004). Selection from perceptual and conceptual representations. Cogn. Affect. Behav. Neurosci. 4, 466-482.

Kaushanskaya, M., and Marian, V. (2007). Non-target language recognition and interference in bilinguals: evidence from eye tracking and picture naming. Lang. Learn. 57, 119-163.

Köpke, B., and Nespoulous, J. (2006). Working memory performance in expert and novice interpreters. Interpreting 8, 1-23.

Kroll, J. F., and Link, J. (2007). "Representation and skill in second language learners and proficient bilinguals," in Cognitive Aspects of Bilingualism, eds I. Kecskes and L. Albertazzi (New York: Springer), 237-269.

Kroll, J. F., and Stewart, E. (1994). Category interference in translation and picture naming: evidence for asymmetric connections between bilingual memory representations. J. Mem. Lang. 33, 149-174.

Lambert, S., Daró, V., and Fabbro, F. (1995). Focalized attention on input vs. output during simultaneous interpretation: possibly a waste of effort. Meta Trans. J. 40, 39-46.

Linck, J. A., Hoshino, N., and Kroll, J. F. (2008). Cross-language lexical processes and inhibitory control. Ment. Lex. 3, 349-374.

Liu, M. (2008). "How do experts interpret? Implications from research in interpreting studies and cognitive science," in Efforts and Models in Interpreting and Translation Research. A Tribute to Daniel Gile, eds G. Hansen, A. Chestermanand, and H. Gerzymisch-Arbogast (Amsterdam: John Benjamins), 159-178.

Lu, C., and Proctor, R. (1995). The influence of irrelevant location information on performance: a review of the Simon and spatial strop effects. Psychon. Bull. Rev. 2, 174-207.

Macizo, P., and Bajo, M. T. (2006). Reading for repetition and reading for translation: do they involve the same processes? Cognition 99, 1-34.

Macizo, P., Bajo, M. T., and Martín, M. C. (2010). Inhibitory processes in bilingual language comprehension: evidence from Spanish-English interlexical homographs. J. Mem. Lang. 63, 232-244.

Maguirre, E. A., Gadian, D. G., Johnsrude, I. S., Good, C. D., Ashburner, J., Frackowiak, R. S., and Frith, C.
D. (2000). Navigation-related structural changes in the hippocampus of taxi drivers. Proc. Natl. Acad. Sci. U.S.A. 97, 4398-4403.

Martin-Rhee, M., and Bialystok, E. (2008). The development of two types of inhibitory control in monolingual and bilingual children. Biling. Lang. Cogn. 11, 81-93.

Mechelli, A., Crinion, J. T., Noppeney, U., O’Doherty, J., Ashburner, J., Frackowiak, R. S., and Price, C. J. (2004). Structural plasticity in the bilingual brain. Nature 431, 757

Meuter, R. F. I., and Allport, A. (1999). Bilingual language switching and naming: a metrical costs of language selection. J. Mem. Lang. 40, 25-40.

Miyake, A., Friedman, N. P., Emerson, M. J., Witzki, A. H., Howerter, A., and Wager, T. D. (2000) The unity and diversity of executive functions and their contributions to complex "frontal lobe" tasks: a latent variable analysis. Cogn. Psychol. 41, 49-100.

Miyake, A., Just, M. A., and Carpenter, P. A. (1994). Working memory constraints on the resolution of lexical ambiguity: maintaining multiple interpretations in neutral contexts. $J$. Mem. Lang. 33, 175-202.

Morton, J. B., and Harper, S. N. (2007). What did Simon say? Revisiting the bilingual advantage. Dev. Sci. 10, 719-726.

Padilla, F., Bajo, M. T., and Macizo, P. (2005). Articulatory suppression in language interpretation: working memory capacity, dual tasking and word knowledge. Biling. Lang. Cogn. 8, 207-213.

Prior, A., and MacWhinney, B. (2010). A bilingual advantage in task switching. Biling. Lang. Cogn. 13, 253-262.

Rodriguez-Fornells, A., Van der Lugt, A., Rotte, M., Britti, B., Heinze, H. J., and Munte, T. F. (2005). Second language interferes with word production in fluent bilinguals: brain potential and functional imaging evidence. J. Cogn. Neurosci. 17, 422-433.

Ryan, J. D., Bialystok, E., Craik, F. I. M., and Logan, J. (2004). Bilingual advantages in attentional control. Poster Presented at the Meeting of the Cognitive Neuroscience Society, San Francisco, CA.

Salvatierra, J., and Roselli, M. (2010). The effect of bilingualism and age on inhibitory control. Int. J. Biling 15, 26-37.

Schneider, W., Eschman, A., and Zuccolotto, A. (2002). E-Prime User's Guide. Pittsburgh, PA: Psychology Software Tools.

Simon, J. R. (1990). "The effects of an irrelevant directional cue on human information processing," in Stimulus-Response Compatibility: An Integrated Perspective, eds W. Proctor and T. G. Reeve (Amsterdam: North-Holland), 31-88.

Sims, V. K., and Mayer, R. E. (2002). Domain specificity of spatial expertise. The case of video game players. Appl. Cogn. Psychol. 16, 97-115.

Spelke, E., Hirst, W., and Neisser, U. (1976). Skills of divided attention. Cognition 4, 215-230.

Conflict of Interest Statement: The authors declare that the research was conducted in the absence of any commercial or financial relationships that could be construed as a potential conflict of interest.

Received: 07 March 2011; accepted: 13 October 2011; published online: 28 October 2011.

Citation: Yudes C, Macizo $P$ and Bajo $T$ (2011) The influence of expertise in simultaneous interpreting on non-verbal executive processes. Front. Psychology 2:309. doi: 10.3389/fpsyg.2011.00309

This article was submitted to Frontiers in Cognition, a specialty of Frontiers in Psychology.

Copyright (c) 2011 Yudes, Macizo and Bajo. This is an open-access article subject to a non-exclusive license between the authors and Frontiers Media SA, which permits use, distribution and reproduction in other forums, provided the original authors and source are credited and other Frontiers conditions are complied with. 